\title{
Coleções fotográficas: discussões em torno do processo de intervenção arquivística
}

\section{Tatiele Araujo da CostaI}

http://orcid.org/0000-0002-6044-1567

\section{Mateus de Moura Rodrigues ${ }^{I I}$}

http://orcid.org/0000-0001-6202-6028

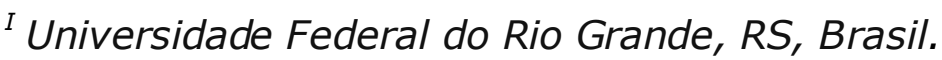

Especialista em arquivos permanentes.

${ }^{I I}$ Universidade Federal do Rio Grande, RS, Brasil.

Professor do Curso de Arquivologia.

\section{http://dx.doi.org/10.1590/1981-5344/3351}

O presente artigo traz uma discussão em torno do processo de intervenção arquivística realizado ao acervo fotográfico do Memorial Cel. Claudino do $6^{\circ}$ Batalhão de Polícia Militar de Rio Grande, abordando o processo de digitalização, onde foi possível analisar os resultados obtidos em dois equipamentos distintos e elencar prós e contras do processo. Após, foi realizada a busca por personagens para obtenção de relatos que fornecessem a descrição das peças. Em caráter complementar, abordase $o$ uso de ferramentas digitais para identificar $e$ acrescentar descrições. Logo, criou-se um catálogo seletivo como instrumento de pesquisa para fornecer organizadamente as descrições obtidas, a partir da Norma Brasileira de descrição arquivística - NOBRADE. Logo, a última etapa do processo foi a inserção das peças fotográficas e suas descrições em um blog criado de forma a disseminar o acervo e possibilitar uma interação dos visitantes à ferramenta possibilitando a colaboração nas descrições expostas. 
Palavras-chave: Fotografias. Digitalização. Descrição. Catálogo.Blog.

This article discusses the process of archival intervention carried out to Memorial Cel's photographic collection. Claudino of the 6th Military Police Battalion of Rio Grande, addressing the digitalization process, where it was possible to analyze the results obtained in two different equipment and list the pros and cons of the process. Afterwards, the search for characters was performed to obtain reports that provided the description of the pieces. In a complementary character, the use of digital tools to identify and add descriptions is addressed. Soon, a selective catalog was created as a research tool to provide the descriptions obtained in an organized manner, based on the Brazilian Standard for Archival Description NOBRADE. Therefore, the last step of the process was the insertion of the photographic pieces and their descriptions in a blog created in order to disseminate the collection and to allow visitors to interact with the tool, enabling collaboration in the exposed descriptions.

Keywords: Photos. Scanning. Description. Catalog. Blog.

Recebido em 22.11.2017 Aceito em 20.11.2020

\section{Introdução}

Fotografias são itens que nos proporcionam entendimento de determinado tempo, história e/ou lugar apenas em um rápido olhar, o que fez com que levasse certo tempo para alcançarem autonomia enquanto documento. A descrição deste documento trabalha diversos pontos, sendo um processo influenciado pela conotação, cultura atual e interpretação individual do descritor, o que faz com quea atividade de descrição em fotografias se torne complexa.

$\mathrm{Na}$ medida em que se expande o conhecimento arquivístico e a sociedade evolui nas questões de gestão dos documentos, a descrição se torna um processo cada vez mais adotado pelas instituições, porém de forma tardia em maioria das vezes. De um modo geral e abrangente, a descrição de fotografias possibilita a identificação de elementos intrínsecos 
e extrínsecos às fotografias, dando voz ao contexto em que a mesma foi produzida para seu pesquisador ou usuário.

Entretanto, o processo de descrição deve sempre vir em conjunto com o acesso e tendo sempre o questionamento de "descrever para quem?". Assim, a escolha de um instrumento de pesquisa que forneça os elementos descritos aos pesquisadores deve sempre ser prioridade. Após esta escolha, deve-se pensar na difusão de todo trabalho realizado.

Blaya Perez (2005, p. 7), detalha melhor esta função arquivística, explicando que este processo "vem a ser a divulgação, o ato de tornar público, de dar a conhecer o acervo duma instituição assim como os serviços que esta coloca à disposição dos seus usuários".

Diante disso, aborda-se aqui as metodologias utilizadas no processo de intervenção arquivística da coleção fotográfica do Memorial Cel. Claudino do $6^{\circ}$ Batalhão de Polícia Militar de Rio Grande. A pesquisa contou com as atividades de digitalização da coleção, descrição arquivística, criação de um instrumento de pesquisa e a criação de uma ferramenta virtual para inserção das atividades mencionadas anteriormente para sua difusãoao meio externo.

De acordo com Ribeiro (1987, p. 32), o Batalhão, na época chamado de Companhia de Guardas, foi criado e instalado provisoriamente no cais do porto em 6 de abril de 1936, pelo Decreto Lei No 6197 com a finalidade defortificar e policiar o único porto marítimo do Estado. A Companhia de Guardas originou-se primeiramente da $3^{a}$ Companhia do Batalhão de Infantaria Montadacuja sede situava-se em Pelotas. No dia 15 de novembro de 1941, foi inaugurado o novo quartel da Companhia, localizado na Avenida Honório Bicalho No 20, onde permanece até hoje. Em 25 de março de 1943, pelo Decreto Lei 236, passou a ser denominado "Batalhão de Guardas". Em 21 deabril de 1961, o Decreto Lei 12.280 modificou o nome para $3^{0}$ Batalhão de Guardas. Nova mudança de nome voltou a acontecer em 18 de dezembro de 1968 para 40 Batalhão de Polícia Militar Btl. Cel. Camilo, vindo a se chamar "Batalhão" pelo fato de assumir o policiamento ostensivo do Estado.

Em 12 de Junho de 1970, a última mudança no nome foi feita baseadano Decreto No 20.237, de 10 de junho do mesmo ano, passando de $4^{\circ}$ para $6^{\circ}$ Batalhão de Polícia Militar. A denominação "60" ocorreu a fim de manter ohistórico da OPM, já que a mesma foi a sexta unidade da corporação criada, tendo como patrono o Coronel Claudino Nunes Pereira, nome dado ao Memorial criado em 2011.

O $6^{\circ}$ BPM possui a missão constitucional de Polícia Ostensiva e a de preservação da ordem pública nas áreas urbanas, rurais e balneárias dos municípios de Rio Grande, São José do Norte, Santa Vitória do Palmar e Chuí, através de processos a pé, montado, motorizado e com a suplementação de cães. Atualmente, o $6^{\circ}$ Batalhão de Polícia Militar de Rio Grande localiza-se na Av. Honório Bicalho, bairro Vila Militar em um 
prédio antigo, fundado em 1941 contando com dois andares e um pátio de tamanho expressivo. O Batalhão possui por atividade fim aquelas relacionadas à segurança pública dos municípios designados (Rio Grande, São José do Norte e Santa Vitória do Palmar) e por atividade meio as relacionadas ao pessoal, material, patrimônio, efetividade, férias, viaturas, consertos, dentre outras.

A partir das atividades de intervenção propostas, fez-se possível analisar as dificuldades e o incremento obtido a todos os processos, trazendo a discussão sobre como foram desenvolvidos e abordando pontos de melhoria às atividades

\section{Coleções fotográficas}

Ao longo do tempo, diversos suportes foram utilizados como, por exemplo, o metal, folhas de ferro laqueado, vidro, papel, plástico, papéis resinados e a famosa fotografia. Mosciaro (2009) explica que a fotografia se define como o resultado de um processo que permite registrar e reproduzir, através de reações químicas em superfícies preparadas para o efeito, pela ação de energia radiante, ou seja, luz.

Em meio arquivístico, a fotografia começou a ser abordada enquanto coadjuvante e não como documento de arquivo. Esta conceituação se deu por autores que acreditavam que o material fotográfico deveria ser usado como componente aos registros como forma de aprimorar informações contidas em documentos textuais.

No decorrer do tempo, já quando o conceito de documento de arquivo foi tomando forma, a fotografia foi então item alvo de questionamentos sobre sua inclusão em meio a acervos enquanto documento, sendo este fato o norteador de diversos conceitos de sua atuação. $O$ autor a trazer essa inserção do documento em suas diversas formas foi Schellenberg ${ }^{1}$ em sua obra "arquivos modernos (2006)", trazendo não só as fotografias inseridas em arquivos como outros diversos, em suas mais variadas formas. Outro autor que aborda múltiplas questões e atualiza constantemente os conceitos que permeiam o material fotográfico é Boris Kossoy².

\footnotetext{
${ }^{1}$ Theodore Roosevelt Schellenberg nascido em 24 de fevereiro de 1903 em Garden Township, Kansas, EUA, foi um arquivista estadunidense, criador dos conceitos de valor primário e secundário dos documentos. Disponível em: https://josi-pr.blogspot.com.br/2016/07/resenha-schellenberg-theodore-r.html

${ }^{2}$ Nasceu em São Paulo em 1941, tendo se firmado desde a década de 1970 como um dos principa is teóricos e historiadores da fotografia no Brasil. Disponível em: http://www.funarte.gov.br/brasilmemoriadasartes/acervo/infoto/biografia-deboris-kossoy/
} 
Kossoy (2001) evidencia que ao mesmo tempo em que a fotografia atua como um registro físico e que contextualiza um momento da história, ela atua na relevância de seu valor informativo. Isso só reforça a importância deste material enquanto documento.

Registrar os fatos importantes é uma forma de os homens comprovarem suas trajetórias e realizações. Como meio de recordação e documentação da vida familiar, como meio de informação e divulgação dos fatos, como forma de divulgação artística ou mesmo como instrumento de pesquisa científica, a fotografia tem feito parte indissociável da experiência humana. (KOSSOY, 2001, p. 155).

A importância da informação de uma fotografia é propiciada na medida em que ela contextualiza a história em seus segmentos, sejam eles sociais, políticos, econômicos, religiosos, culturais etc. Freund (1995), por exemplo, acredita que a importância da fotografia ultrapassa seus conceitos de registro histórico e se torna também um instrumento formador de opinião pública com capacidade de despertar diferentes leituras e visões de uma mesma realidade. Portanto, a partir de seu conceito, a fotografia apresenta contexto histórico e cultural.

Para Kossoy (1999) a fotografia fornece provas como um documento, retratando a realidade de uma sociedade e seus valores culturais, além da memória de sua população. Portanto, entende-se que a fotografia se apresenta como um documento histórico de extrema importância que se utiliza para eternizar determinados momentos de uma história.

Já faz algum tempo que as coleções, que um dia foram vistas apenas como peças de museus, começaram a se disseminarem nos arquivos, fazendo-os passarem de produtores para também custodiadores. Para o Arquivo Nacional (2005, p. 52), coleção é o "conjunto de documentos com características comuns, reunidos intencionalmente". Silva (2008) esclarece quando diz que,

Os museus trabalham com coleções. O que vimos até agora é que os documentos de arquivo não são colecionados, eles são produzidos pela instituição e existe legislação respaldando as atividades. Mas os museus colecionam documentos que, muitas vezes, foram retirados de seu contexto por diversas razões, e foram vendidos ou doados a museus, arquivos e bibliotecas. Assim, eles acabam sendo 
considerados como peças isoladas, recebendo tratamento individualizado. (SILVA, 2008, p. 65-66).

Segundo Silva (2013), quando se trata de alocar documentos em museus de forma conjunta, as características das peças passam a ser diferentes, situação que ainda é pouco explorada na bibliografia brasilei ra. Roberts (200?) diz que os arquivos de museus abordam pelo menos três características de documentos como sendo partes de uma coleção, sendo elas os mapas, fotografias, artefatos e audiovisuais; os documentos que compõem os registros do acervo portando informações de proveniência e os documentos gerados pela funcionalidade do próprio arquivo museu. Assim, acredita-se que as coleções tenham a função de servir como uma fonte de informação sobre a história de modo a evidenciar e disseminar seus registros a partir de uma temática.

\section{Digitalização}

Com a crescente onda de disseminação de conteúdos pelas redes de informação existentes, necessitou-se de um processo que levasse os documentos do físico ao virtual, criando-se assim o processo de digitalização. Este processo possui como maior finalidade a inclusão de uma cópia do documento em meio digital, resultante das demandas de acesso aos acervos existentes para fins de consulta.

O processo de digitalização não é simples, necessitando de atualizações e recursos de forma constante, além de conhecimento de fatores tecnológicos. A responsabilidade principal deste processo se dá quanto à resolução, compressão e armazenamento da imagem, evitando perdas, garantindo qualidade no processo e fornecimento de uma ampla capacidade de armazenamento. Portanto, na escolha deste processo devese levar em consideração questões de custo, tempo, qualidade e uso, que não são simples.

Segundo o Conselho Nacional de Arquivos (Conarq) (2010), se no âmbito organizacional, o processo de digitalização busca agilidade no acesso, em âmbito arquivístico busca-se identificação, autenticação e diminuição do manuseio periódico que pode vir a fragilizar a forma e o conteúdo dos documentos. Entretanto, deve-se considerar que o processo de digitalização não deve ser visto como atividade de preservação, pois ao mesmo tempo que diminui a necessidade de contato com a original evitando o avanço de sua degradação, aumenta as chances de que o documento original seja abandonado.

Ainda assim, para o processo se faz necessário cuidados a respeito do processamento e apresentação do documento após a digitalização, pois a inadequação destes preceitos pode levar à inacessibilidade do conteúdo. Além disso, a arquivística considera relevante também as questões éticas, 
legais e as que envolvem a proteção e confidencialidade em determinados casos.

Quanto à legislação que rege a utilização do processo, têm-se regras básicas sobre a digitalização para geração de cópias, para acesso e para preservação de documentos que já se encontram em deterioração. Ainda se questiona o fato de utilizar o processo com o intuito de substituição, onde a cópia substitui o documento original. Neste caso, a legislação traz pontos como a falta de garantia que o processo proporciona, não recomendando a eliminação do original já que o processo cria apenas uma cópia do documento, podendo ela não ser autêntica e confiável.

De acordo com o Conarq (2010, p. 7), para a obtenção de um processo de digitalização de qualidade,

É necessário que os equipamentos utilizados possibilitem a captura digital de um documento arquivístico de forma a garantir a geração de um representante digital que reproduza, no mínimo, a mesma dimensão física e cores do original em escala $1: 1$, sem qualquer tipo de processamento posterior através de softwares de tratamento de imagem. (CONARQ, 2010, p. 7).

Para isto, os equipamentos escolhidos para o processo devem garantir aos representantes digitais a melhor fidelidade visual em relação aos documentos originais, e sem comprometer seu estado de conservação. Os equipamentos existentes são os escâneres de mesa, escâneres planetários, câmeras digitais, equipamentos para a digitalização de negativos e diapositivos fotográficos, equipamentos para digitalização de microformas e escâneres de produção e alimentação automática.

Para o Conarq (2010), escâneres de mesa são indicados a documentos planos em folhas simples e ampliações fotográficas contemporâneas, além de possuírem um bom estado de conservação. Nestes equipamentos não são digitalizados documentos encadernados. Os escâneres planetários são mesas de reprodução com a forma de captura semelhante a uma câmera fotográfica, definindo a área de escaneamento e uma fonte de luz. Nestes pode-se digitalizar documentos simples, encadernados (necessitando a compensação da lombada) e documentos fisicamente frágeis, já que neste equipamento não ocorre nenhum tipo de pressão ao documento.

Para o Conarq (2010), as câmeras digitais necessitam do uso de mesas de reprodução, a fim de garantir a estabilidade necessária e uma boa qualidade de imagem, devendo acompanhar sistemas de iluminações compatíveis. Este equipamento deve ser usado caso não haja a possibilidade de utilização desistemas planetários. 
De acordo com o manual do Conarq (2010), para os negativos e diapositivos fotográficos, deve-se utilizar escâneres específicos que sejam, preferencialmente, multiformato (adaptado para manuseio de diversos formatos e tipos de filme fotográfico) e que possuam suporte flexível e estejam em bom estado de conservação. Negativos e diapositivos não podem ser digitalizados neste tipo de equipamento devido ao risco de operação dos dispositivos mecânicos e ópticos.

Para o Conarq (2010), a digitalização de microformas deve ser feita por equipamentos específicos garantindo a fidelidade ao original. Neste processo, a qualidade das imagens obtidas pode variar de acordo com o estado dos filmes digitalizados. Já os escâneres de produção e alimentação automática possibilitam maior velocidade no processo de digitalização de grandes volumes de massa documentais. Porém, a utilização deste equipamento deve ser avaliada devido ao risco de danos físicos de redução da conservação dos documentos, já que para este processo faz-se necessárioo contato direto do documento original à exposição luminosa artificial intensa e ao calor imposto pelo equipamento.

Em relação aos formatos utilizados no processo de digitalização, o Conarq (2010) recomenda os formatos abertos que permitem melhores condições de acesso e preservação, sem a dependência de softwares e hardwares. Os formatos mais utilizados são o TIFF (Tagged Image File Format), PNG (Portable Network Graphics) e JPEG (Joint Photographics Experts Group).

De acordo com o Conarq (2010), o formato TIFF apresenta uma maior definição de cores, além de possuir a sua utilização para o intercâmbio de representantes digitais entre várias plataformas de tecnologias. O formato PNG utiliza a compressão sem perdas, mas é limitado na inserção de metadados embutidos. O formato JPEG é utilizado para a geração de matrizes quando os originais em outros formatos continuam a serem preservados, mas possuem limitações em navegação WEB, devendo ocorrer a geração de uma imagem derivada de acesso em formato JPEG. Este formato também pode ser utilizado para a compressão sem perdas e em relação a outros formatos, permite embutir mais metadados.

Portanto a utilização do processo de digitalização deve obedecer a critérios propostos, priorizando a integridade física do documento digital, as propostas de acesso, a finalidade de sua utilização, além da escolha correta dos equipamentos e formatos de acordo com as necessidades do documentode arquivo e/ou coleção.

\section{Descrição arquivística}

Na década de 1980, a comunidade arquivística, representada pelo Conselho Internacional de arquivos (CIA), reuniu-se para o debate sobre a 
criação de uma norma descritiva internacional, a fim de padronizar a descrição de documentos. Mas, somente após a criação do Comitê de Normas de Descrição pelo CIA, em 1989, que a representação das informações arquivísticas, fornecendo controle e acesso, passou a ser vista como uma das etapas essenciais do trabalho arquivístico. A partir daí a descriçãoé vista como a atividade que possibilitou que as informações contidas nas séries e/ou unidades documentais se tornassem acessíveis aos pesquisadores, de modo a relatar o acervo ou parte dele por meio de instrumentos de pesquisa que facilitem o acesso.

O Arquivo Nacional (2005, p. 67), apresenta o conceito de que descrição é o "Conjunto de procedimentos que leva em conta os elementos formais e de conteúdo dos documentos para elaboração de instrumentos de pesquisa".

Para autores como Bellotto (2006), o processo descritivo exige diversos conhecimentos a fim de que o descritor saiba resumir conteúdo sem corromper informações; extrair dos documentos os assuntos; dos assuntos os conceitos; dos conceitos os descritores; além de estabelecer relações. Além destas, a descrição possibilita ao arquivista a tarefa de analisar os tipos diplomáticos e jurídicos, o conteúdo, o lugar e data, relações externas e demais dados para a sua organização.

Acredita-se que a descrição se faz necessária como instrumento de promoção dos arquivos aos pesquisadores. Baseando-se nisso, a descrição deve ser uma atividade realizada de forma exata, de acordo com os testemunhos da informação; suficiente, identificando fundo, série ou documento com informações necessárias; e oportuna, refletindo a hierarquia de informações. Lopez (2002), entretanto, evidencia que a descrição deve também levar em conta o caráter orgânico encontrado nas séries e subséries e o caráter estrutural dos fundos, subfundos, seções, subseções, grupos e subgrupos, sejam eles quais forem.

Cabe lembrar que aqui defende-se a ideia de que a descrição não deva ser um processo realizado apenas em documentos de caráter permanente como defendido por muitos autores, mas sim, principalmente em documentos de idade corrente. Neste aspecto, há quem acredite que a descrição de arquivos correntes deve ser distinta da forma que é realizada nos arquivos permanentes, uma vez que, em arquivos permanentes o objetivo central é a pesquisa de um público amplo e diversificado, devendo assim conter mais elementos informativos sobre os documentos. Já aos arquivos correntes, não se deve fazer necessário o levantamento de todas as informações, já que o usuário está na base da produção dos documentos.

\section{Instrumentos de pesquisa}


Instrumento de pesquisa arquivístico é caracterizado como uma ferramenta utilizada para descrever todo um arquivo ou parte dele, com a função de simplificar e normalizar a consulta dos documentos, determinando quais são e onde se localizam. Define-se como:

Obra de referência, publicada ou não, que identifica, localiza, resume ou transcreve, em diferentes graus e amplitudes, fundos, grupos, séries e peças documentais existentes num arquivo permanente, com a finalidade de controle e de acesso ao acervo. (ARQUIVO NACIONAL apud LOPEZ, 2002. p. 64).

Segundo Lopez (2002), os instrumentos de pesquisa são ferramentas de acesso e controle para acervos, normalmente permanente; o que não justifica a descrição apenas nesta fase. Os instrumentos possuem como função principal disponibilizar documentos ao acesso e consulta para diversos fins e são classificados e apresentados na forma de guias, inventários, catálogos e índices. Seja qual for o elaborado, esta ferramenta é o que situa os pesquisadores, sejam eles internos ou externos ao arquivo.

A criação de um instrumento também pode ser considerada uma medida de preservação aos documentos, uma vez que criado, é possível saber se o documento se localiza ou não junto ao acervo, evitando que os documentos sejam manuseados, aumentando os riscos de degradações. De uma forma geral, os instrumentos de pesquisa são o que propiciam uma grande difusão aos acervos, podendo ser publicados em meios impressos ou eletrônicos de acordo com a vontade e necessidade da instituição detentora do acervo.

De forma simplificada, os guias são definidos como "Instrumento de pesquisa que oferecem informações gerais sobre fundos e coleções existentes em um ou mais arquivos". (ARQUIVO NACIONAL, 2005, p.102). Este instrumento possui como finalidade primordial possibilitar uma visão do conjunto de serviços de arquivo que uma determinada instituição fornece, de modo a permitir ao pesquisador saber quais são os recursos disponíveis; sua natureza e o contexto dos fundos que ela abriga; os instrumentos de pesquisa existentes e suas fontes complementares, sendo assim, um instrumento bem mais completo.

Lopez (2002) ainda complementa que o guia possibilita evidenciar os dados gerais da instituição e as suas condições de consulta ao acervo, além de trazer consigo a descrição sumária dos fundos e coleções. O guia pode ser também classificado como guia de fontes, quando remeter a fundos, grupos ou séries de um ou mais arquivos que possuam um determinado tema ou guia especializado, onde são descritos fundos ou 
núcleos documentais de arquivos ou outras entidades custodiadoras, agrupando-os por fatores temáticos ou cronológicos.

O inventário por sua vez, é um instrumento que possui a série como base descritiva, contemplando a descrição exaustiva ou parcial de um fundo. Normalmente é dividido em duas partes distintas, sendo a primeira a introdução de forma sumária o conjunto a ser descrito enquanto a segunda especifica o conteúdo de cada série.

Outro instrumento facilmente encontrado é o catálogo. De acordo com a definição do Arquivo Nacional, é um "instrumento de pesquisa organizado segundo critérios temáticos, cronológicos, onomásticos ou toponímicos, reunindo a descrição individualizada de documentos pertencentes a um ou mais fundos, de forma sumária ou analítica". (ARQUIVO NACIONAL, 2005, p.45). Os catálogos são considerados instrumentos voltados para a descrição analítica das peças documentais que compõem o acervo, fazendo a dita varredura documento por documento. Este instrumento ainda pode ser encontrado como catálogo seletivo, o qual se refere à descrição de unidades documentais a partir de critérios temáticos, contemplando em vezes, documentos de fundos distintos.

Bellotto (2006) apresenta que o catálogo seletivo pode vir a se referir a temas, pessoas ou eventos específicos, podendo ainda trazer os documentos considerados mais importantes ou de maior interesse. Assim, seu objetivo é o agrupamento dos documentos de mesmo assunto, mesmo tempo ou a respeito das mesmas pessoas ou lugares existentes em um ou mais fundos.

Por fim, o índice é, "a relação sistemática de nomes de pessoas, lugares, assuntos ou datas contidas em documentos ou em instrumentos de pesquisa, acompanhados das referências para sua localização" (ARQUIVO NACIONAL, 2005, p. 107). É o instrumento que visa apontar nomes, lugares ou assuntos em ordem alfabética a fim de remeter 0 usuário a uma rápida e ágil localização dos documentos do acervo. Portanto, o objetivo do índice é permitir uma rápida localização das unidades documentais que atendam a critérios específicos, tanto de uma única série como de diferentes fundos.

\section{Internet como meio de difusão}

Com a evolução humana, a internet foi criada possibilitando uma nova fase de produção e autoria de informações. Com uma vasta gama de ferramentas, a evolução da internet passou a ser conhecida como Web 2.0. Desta forma, o acesso à informação passou a ser difundida de forma virtual com uma maior facilidade a alcance. 
A difusão é uma das funções arquivísticas que objetiva dispor informações aos receptores, o que na vertente dos arquivos pode ser entendido como espalhar a informação contida no acervo para além de suas paredes. A difusão é muito utilizada para dar conhecimento a sociedade dos serviços e produtos que o arquivo dispõe.

Outro ponto que a difusão permite ao acervo é a captação de recursos a partir dos meios de difusão utilizados, como, por exemplo, uma exposição aberta ao acervo que demonstre a importância da pesquisa em seus documentos, o que acaba por resultar em empresas parceiras e colaborativas com verbas ou então voluntários para ajuda na execução dos serviços. Estes e muitos outros são pequena parte dos meios de difusão a serem pensados para que o reconhecimento da importância do arquivo seja obtido.

Com o conhecimento amplo do que a difusão é capaz de propiciar ao arquivo, nota-se que a internet pode ser uma grande aliada neste processo. A internet pode vir a ser um canal para que a informação vá até um vasto número de usuários, os quais não seriam alvos em exposições presenciais no acervo. $O$ alcance da internet faz com que este processo seja distribuído de forma a atingir um diversificado perfil de pessoas, podendo ainda, fazer com que o processo de difusão vá ainda mais longe.

Com a diversificada quantidade de ferramentas que a internet possibilita, se faz possível a criação de diversos meios de difusão online como, criação de páginas em redes sociais, exposição de peças documentais, além da colaboração na pesquisa de elementos descritivos a partir da interação com os usuários, o que enriquece o trabalho do profissional arquivista.

Uma das ferramentas popularmente utilizadas para disseminação de informações atualmente são os blogs. Segundo Primo (2008), a palavra blog tem origem no termo weblog, a qual é formada por duas palavras; web que significa página de internet e $\log$, diário debordo. De acordo com Pontes e Filho (2011), o blog surgiu no final dos anos 90 como um diário virtual que contemplava o compartilhamento de ideias, relatos, pensamentos pessoais, entretanto, exigia um técnico conhecimento de programação. Os primeiros aplicativos de serviços de blogs gratuitos surgiram em 1999, como, por exemplo, o Blogger. Com a criação deste tipo de ferramenta, possibilitou-se que qualquer pessoa se tornasse um blogueiro.

Os blogs possibilitam a criação de páginas, chamadas de posts, e a inserção de comentários possibilitando o diálogo entre o autor e o públicoalvo, incentivando a interação dos usuários com tema discutido. De acordo com Portella (2012);

Um blogue típico combina texto, imagens e links para outros blogues, páginas da web e mídias relacionadas a seu tema. 
A possiblidade dos leitores deixarem comentários é uma forma de interagir com o autor e outros leitores. Alguns sistemas de criação e edição de blogues são muito atrativos pelas facilidades que oferecem, disponibilizando ferramentas próprias que dispensam o conhecimento de linguagens próprias de informática. (PORTELLA, 2012).

Diante dessa possibilidade, os blogs começaram a ser utilizados não só para uso pessoal, mas para disseminação de produtos e serviços prestados por empresas e afins. Desta forma, a internet forneceu subsídios que colaborassem com a difusão de todo o tipo de conteúdo, incluindo os acervos produzidos e/ou custodiados pelos arquivos.

\section{Metodologia}

Quanto ao ponto de vista da sua natureza, segundo Silva e Menezes (2005), a pesquisa classifica-se como sendo básica a fim de gerar conhecimentos para o avanço da ciência. Já do ponto de vista da forma de abordagem do problema, a pesquisa se caracteriza como qualitativa, pois não necessitou do uso de técnicas e métodos estatísticos, e sim a interpretação dos fatos e a pertinência dos seus significados. De acordo com Gil (1991), os objetivos da pesquisa são exploratórios já que o intuito da pesquisa é fazer com que a análise do processo em determinado ambiente estimule a compreensão.

Em meio ao desenvolvimento da pesquisa, utilizou-se da pesquisa bibliográfica que permeassem o assunto sobre as metodologias utilizadas nos processos de digitalização, descrição, criação de instrumentos de pesquisa e difusão, além das características das coleções fotográficas. Entretanto o estudo experimental foi utilizado pelo fato de propiciar aobservação das variáveis que pudessem influenciar o processo, analisando-se assim, os efeitos produzidos nas intervenções arquivísticas ao acervo do $6^{\circ} \mathrm{BPM}^{3}$.

A seguir serão abordados os procedimentos realizados em cada atividade proposta e implementada à coleção fotográfica do Memorial Cel. Claudino.

\subsection{Digitalização e descrição da coleção fotográfica}

A coleção fotográfica do Memorial Cel. Claudino conta ao todo com 32 fotografias datadas em torno dos anos de 1950 a 2011, com diversos tamanhos, orientações e estão expostas na sala do Memorial em expositores de vidro.

Iniciou-se o processo de digitalização da coleção solicitando o empréstimo à instituição a partir de ofício emitido pela Universidade

${ }^{3} 6^{\circ}$ Batalhão de Polícia Militar de Rio Grande. 
Federal do Rio Grande - FURG, a qual cedeu espaço para o processo no Laboratório do Instituto de Ciências Humanas e da Informação (ICHI), além de seus equipamentos.

Em primeiro momento foi feita a preparação das peças, onde foram higienizadas e recuperadas, nos casos em que se encontraram rasgos. Após, iniciou-se a captura da imagem na câmera fotográfica (imagem 1). O escâner com câmera fotográfica possibilitou a captura das fotografias a partir de uma câmera acoplada em sua parte superior, a qual possui um deslocamento de 30 polegadas para cima, uma base de $60 \mathrm{~cm} \times 60 \mathrm{~cm}$ e duas lâmpadas que forneceram iluminação artificial ao processo. Este equipamento foi utilizado por não haver um escâner planetário.

\section{Imagem 1 - Câmera fotográfica}

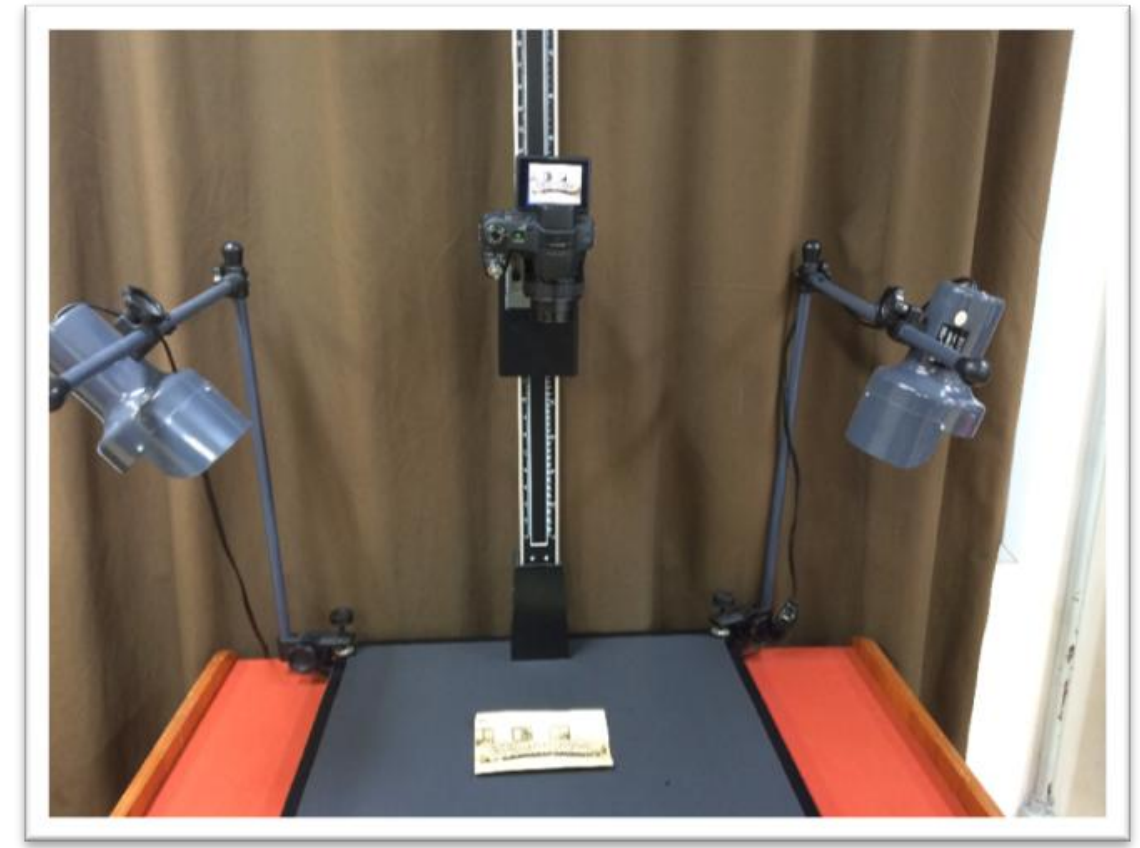

Fonte: Elaborado pelos os autores, 2016

A próxima etapa foi a indexação das imagens capturadas, dando a elas uma identificação, salvando-as em formato TIFF e JPEG conforme o recomendado, armazenando-as em uma pen drive e salvando em nuvens e em outros dispositivos as cópias de segurança

$\mathrm{Na}$ etapa de controle de qualidade, a qual possibilitou uma análise e comparação da imagem capturada com a imagem original, o resultado obtido não foi satisfatório. A insatisfação se deu pelas interferências na captura da imagem, as quais constavam reflexos do vidro utilizado para estabilização da imagem, dos raios de sol que entravam pelas janelas do laboratório e pela própria iluminação do espaço. Entende-se que isto se deve a sala utilizada, a qual não foi construída especificamente para realização de processos como este. 
Com a possibilidade de utilização de outro equipamento disponível e insatisfação do primeiro processo, decidiu-se repetir a atividade em um escâner de mesa, o qual possibilitaria também, elencar diferenças dos dois equipamentos visando uma investigação.

As mesmas peças fotográficas foram digitalizadas no escâner EPSON PERFECTION V700 PHOTO. O escâner possui uma área de digitalização de $21,6 \mathrm{~cm}$ por $29,7 \mathrm{~cm}$, profundidade de cores de 48 bits interna e 24 bits externa, densidade ótica de 40 Dmax e Resolução ótica de 640 dpi. O equipamento possui o tamanho A4 máximo para cópia, além da possibilidade de aumentar a tampa para digitalização de volumes maiores como, por exemplo, livros. (Imagem 2).

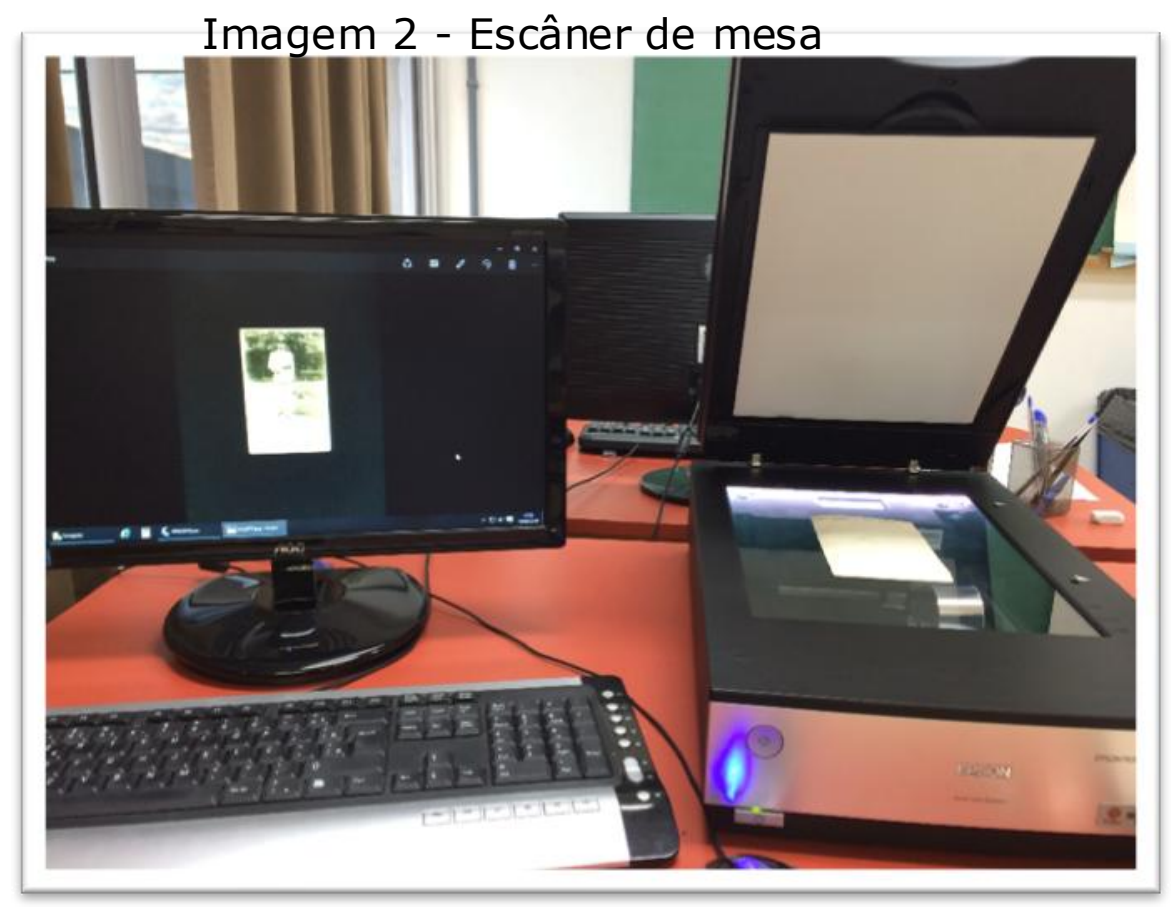

Fonte: Elaborado pelos os autores, 2016

As imagens capturadas foram indexadas da mesma forma que o processo anterior e salva nos respectivos formatos já abordados.

$\mathrm{Na}$ etapa de controle de qualidade, onde foram analisadas as imagens capturas com a fotografia original, verificou-se que o processo foi satisfatório, possibilitando uma qualidade e fidedignidade muito maior que a realizada no processo anterior. Por se tratar de um escâner que possui uma cobertura, a iluminação e os diversos pontos de interferência ocorridos anteriormente não afetaram as imagens, resultando em uma boa captura. Em contrapartida, o tamanho escâner dificultou a realização das margens recomendadas em algumas peças, já que o formato de algumas se igualava ao tamanho do escâner. 
Em se tratar da resolução da captura, ambos os processos tiveram 600 dpi de resolução, a fim de seguir as recomendações do Conarq (2010) que prevê a resolução mínima de 300 dpi, além da utilização da escala de $1: 1,24$ bits ( 8 bits por canal de cor) e margem na cor preta com 0,2 cm ao redor da fotografia, feita a partir de uma base preta de forma improvisada.

Após o fim do processo, as imagens foram devolvidas a instituição de sua custódia.

Em segundo momento foi feita a descrição da coleção. O processo de descrição se deu na busca por pessoas que pudessem oferecer informações a respeito das imagens digitalizadas. O objetivo foi marcar entrevistas com militares ativos, aposentados e simpatizantes que obtivessem algum tipo de relação com o Batalhão nos anos em que as fotografias abarcavam.

Nesta etapa, foi possível contar com a colaboração de seis pessoas que possuíam relações com as fotografias e que poderiam contribuir na coleta dos dados. Foram entrevistados dois policiais militares ativos, que possuíssem grande período de carreira, incluindo a funcionária com 36 anos de serviços prestados e que ainda se encontra em atividade; três policiais militares aposentados, dentre eles um senhor de 89 anos de idade e único personagem ainda vivo de uma das fotografias mais antigas; e a irmã de um dos policiais aposentados que nasceu e cresceu em torno do batalhão, por ter seu falecido pai também policial militar da instituição. Todos os personagens entrevistados foram indicados por membros da instituição.

As entrevistas tinham por intuito a observação das fotografias junto aos participantes a fim de evidenciar os eventos e personagens que compunham as imagens. Ao todo, das 32 peças fotográficas apenas três fotografias do ano de 1950 não foram descritas já que os entrevistados não obtinham conhecimento dos personagens e lugares que as imagens mostravam. Em contrapartida, uma das fotos de mesmo período, apresentando 31 militares, obteve a descrição de 16 personagens a partir da colaboração do Tenente aposentado de 89 anos, o qual evidenciou que por conta da idade avançada, sua memória não colaborou para que mais elementos fossem descritos.

A fim de desenvolver uma enriquecida descrição as peças, em segundo momento foram utilizadas referências bibliográficas, bem como matérias veiculadas em jornais famosos da cidade e na internet sobre os eventos ocorridos em datas aproximadas às das fotografias, referentes ao 60 Batalhão de Polícia Militar. O objetivo era identificar os acontecimentos em mídias que pudessem colaborar com informações a respeito do momento registrado como, objetivo do evento, data exata, órgãos envolvidos, importância do acontecimento para mídia, dentre outros. A 
ideia de utilização das mídias disponíveis colaborou com muitos elementos do processo.

Foram analisadas também imagens existentes de ruas e policiais do mesmo período das peças descritas, a fim de localizar pontos que fornecessem comparações para identificação de lugares e distinção de fardamentos por posição hierárquica, complementando assim o processo descritivo. Diante destas, a pesquisa pôde complementar diversas lacunas na descrição, além de fornecer informações não obtidas em meios utilizados anteriormente.

\subsection{Criação do instrumento de pesquisa e sua difusão pela internet}

Após a descrição estar parcialmente concluída, optou-se pela criação de um catálogo seletivo, enquanto instrumento de pesquisa, a fim de abarcar a descrição desenvolvida à coleção fotográfica do Memorial. O catálogo seletivo foi o instrumento escolhido por se tratar de um número pequeno de peças fotográficas e por ser uma coleção de fotografias com diferentes datas e assuntos, porém reunidas por uma mesma temática, no caso, fotos do $6^{\circ}$ Batalhão de Polícia Militar de Rio Grande.

O instrumento criado visou à contextualização das informações de forma subdividida em unidades, baseada na Norma Brasileira de Descrição Arquivística (NOBRADE), a qual ofereceu a áreas que descrevessem os dados importantes levantados no processo, demonstrada a seguir.

\section{Quadro1 - Áreas utilizadas da NOBRADE}

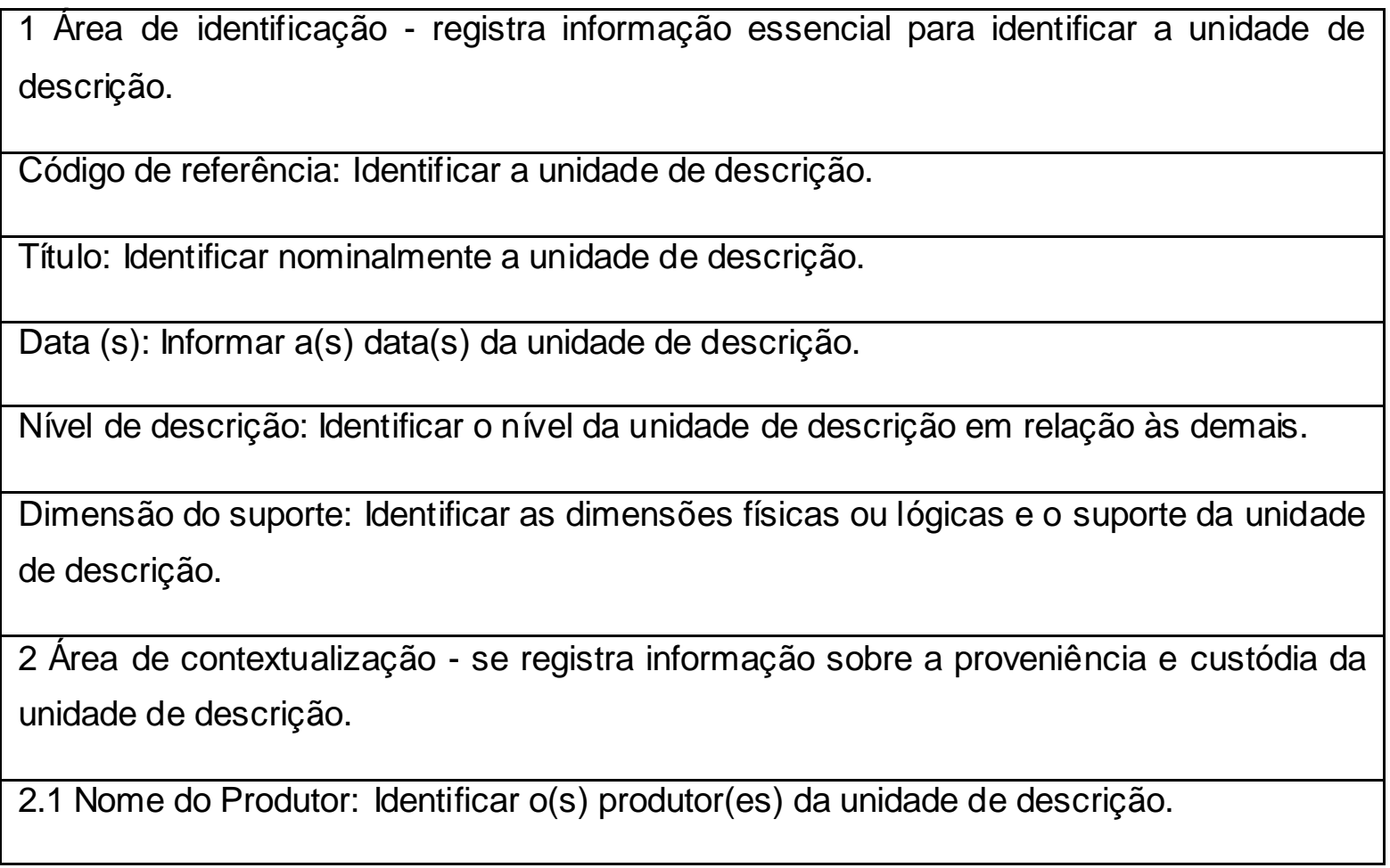


3 Área de conteúdo e estrutura - se registra informação sobre o assunto e a organização da unidade de descrição.

3.1 Âmbito e conteúdo: Fornecer aos usuários informações relevantes ou complementares ao Título (1.2) da unidade de descrição.

3.4 Sistema de arranjo: Fornecer informação sobre a estrutura interna, ordem e/ou sistema de arranjo da unidade de descrição.

4 Área de condições de acesso e uso - se registra informação sobre o acesso à unidade de descrição.

4.1 Condições de acesso: Fornecer informação sobre as condições de acesso à unidade de descrição e, existindo restrições, em que estatuto legal ou outros regulamentos se baseiam.

5 Área de fontes relacionadas - se registra informação sobre outras fontes que têm importante relação com a unidade de descrição.

5.3 Unidade de descrição relacionada: Identificar a existência de unidades de descrição relacionadas.

6 Área de notas -se registra informação sobre o estado de conservação e/ou qualquer outra informação sobre a unidade de descrição que não tenha lugar nas áreas anteriores.

6.1 Notas sobre conservação: Fornecer informações sobre o estado de conservação da unidade de descrição, visando orientar ações preventivas ou reparadoras. (Descrição dos representantes remetendo ao original).

7 Área de controle da descrição - se registra informação sobre como, quando e por quem a descrição foi elaborada.

7.3 Data da descrição: Indicar quando a descrição foi preparada e/ou revisada.

8 Área de pontos de acesso e indexação de assuntos - se registra os termos selecionados para localização e recuperação da unidade de descrição.

8.1 Pontos de acesso e indexação de assuntos: Registrar os procedimentos para recuperação do conteúdo de determinados elementos de descrição, por meio da geração e elaboração de índices baseados em entradas autorizadas e no controle do vocabulário adotado. 
Fonte: Elaborado pelos os autores, 2017

O objetivo principal da criação do catálogo seletivo foi possibilitar um instrumento de pesquisa e acesso às informações não visíveis das fotografias aos pesquisadores internos e externos do Batalhão.

Depois de concluído, o instrumento e suas descrições foram lançados em um blog desenvolvido especialmente para o Memorial a fim de expandir a possibilidade de acesso da coleção e da instituição a usuários externos.

O blog foi criado a partir da ferramenta gratuita de criação de páginas na internet, chamada Blogger ${ }^{4}$. A criação visou a disponibilização das peças fotográficas juntamente com suas descrições, acessível de forma simples e facilitada aso usuários.

Em primeiro momento, tinha-se em mente a criação de uma plataforma arquivística que disponibilizasse de forma online esses produtos, porém, identificou-se que, por se tratar de uma instituição militar, não houve tempo para uma apresentação sobre os benefícios e o funcionamento desta proposta e que para isso, seria necessária a disponibilização de uma máquina para manter a plataforma em funcionamento, o objetivo da proposta não seria executado com total êxito. Diante disso, para que se cumprisse o objetivo de dar o acesso aos usuários externos, decidiu-se pela criação do blog 5 .

O layout e a disposição das informações no blog foram realizados visando à facilidade de navegação e a mínima poluição visual. O mesmo conta com uma breve apresentação do acervo, sua localização a partir de um mapa e links das páginas das redes sociais do Batalhão. À direita, localizam-se os títulos das fotografias que, ao clicar, levam até a imagem e sua descrição. As mesmas contam com links para compartilhamento em diversas redes sociais e caixa de diálogo logo abaixo para inserção de comentários e sugestões. A ferramenta possibilita também a visualização e apuração em número das visitas online ao acervo.

Diante disso, a expectativa é que a ferramenta possibilite o conhecimento a comunidade da existência do acervo e da história da instituição, além da colaboração da sociedade no processo descritivo, colaborando com nomes, datas e elementos para tornar a descrição completa ou corrigir informações já descritas. Assim, o blog passa de apenas uma ferramenta de difusão do acervo para um meio de interação com a comunidade em geral.

Assim, a etapa de maior concentração foi a discussão dos fatos obtidos na atividade realizada anteriormente para uma maior percepção

${ }^{4}$ Disponível em: https://www.blogger.com/

${ }^{5}$ Acesso do blog: memorialcelclaudino.blogspot.com 
da metodologia utilizada e das dificuldades encontradas para obtenção de êxito à atividade.

\section{Resultados e discussões}

Os resultados obtidos quanto ao processo de digitalização possibilitaram uma análise da captura dos diferentes equipamentos disponíveis, a partir do controle de qualidade. Diante disso, a digitalização pelo escâner com câmera fotográfica não foi satisfatória devido à interferência na imagem oriunda da iluminação artificial, além da iluminação natural do ambiente.

Contudo, a captura pelo escâner de mesa foi a mais adequada pelo processo, uma vez que o próprio equipamento impossibilita a incidência de luz externa durante a captura. Em contrapartida, a dificuldade encontrada com o escâner de mesa foi o seu tamanho, dificultando a captura de fotografias em tamanhos próximos ao do equipamento. Quanto ao processo de indexação, os resultados obtidos demonstraram que em se tratar de tamanho de arquivo, o formato JPEG é o recomendado.

Os resultados obtidos na etapa de descrição das fotografias se deram a partir da colaboração de pessoas envolvidas, militares ativos e inativos que poderiam fornecer informações a respeito das imagens do acervo. A colaboração foi muito importante no processo. Contudo, observa-se que a descrição tardia é uma das problemáticas do processo de descrição, uma vez que os personagens e as memórias desaparecem.

Além das entrevistas, a pesquisa bibliográfica colaborou para a descrição de elementos como datas e acontecimentos que foram veiculados na mídia, possibilitando complementar diversas lacunas na descrição.

Quanto à criação do instrumento de pesquisa, a escolha do catálogo correspondeu às expectativas esperadas uma vez que possibilitou a reunião dos elementos descritivos do acervo de fotografias reunidas perante uma temática.

No cumprimento do objetivo de difusão do acervo, a proposta inicial não se fez possível. Em primeiro momento, foi pensado em uma plataforma arquivística como, por exemplo, o ICA-AtoM. Entretanto, devido falta de tempo disponível para treinamento de pessoal e impossibilidade do $6^{\circ}$ BPM em dispor uma máquina para manter a plataforma em constante funcionamento. Desta forma, o objetivo não seria executado com êxito. No entanto, a criação do blog possibilitou o cumprimento do objetivo em fornecer acesso aos usuários externos de forma simples e fácil. 


\section{Considerações Finais}

A partir da experiência apresentada, nota-se claramente a importância da prática dos conhecimentos teóricos adquiridos. A atividade trouxe de forma eficaz as problemáticas e as melhorias que poderiam ou ainda podem ser aplicadas em todos os processos desenvolvidos, já que houve um espaço de tempo determinado para a conclusão de cada etapa.

$\mathrm{Na}$ atividade de digitalização, foi possível evidenciar a utilização de dois equipamentos distintos a partir da análise de suas capturas. Concluiu-se que, diante do local de execução da atividade, o escâner de mesa propiciou um resultado de maior qualidade do que o outro equipamento. Assim, nota-se a importância de todos os detalhes no desenvolver do processo, inclusive da sala de realização do mesmo.

Ainda sobre o processo de digitalização e a partir do cumprimento das recomendações para formato dos arquivos, notou-se que o formato TIFF possui um volume muito maior em pixels que o formato JPEG, e que, dependendo do dispositivo que irá armazenar as imagens, seria inexecutável.

O processo descritivo trouxe maior êxito à proposta de intervenção, possibilitando uma descrição íntegra dos elementos estabelecidos. Porém, as lacunas existentes na descrição ocorreram pela tardia iniciativa de processo, enunciando ainda mais que a descrição precise ser pensada e aplicada assim que o documento for produzido, principalmente em peças fotográficas.

Os contras encontrados no processo de descrição após quase 70 anos de produção de algumas peças foi a falta de personagens que possibilitassem a narração da história de cada fotografia, o que acabou por deixar três imagens sem nenhuma descrição, mas sim suposições.

Posteriormente à descrição e criação do catálogo seletivo propôs a visualização dos elementos descritos da NOBRADE com as informações coletadas, dando ainda mais um viés arquivístico à atividade. Desta forma, os elementos da norma em questão possibilitaram uma ajustada utilização da descrição fornecendo os elementos indispensáveis para entendimento do contexto de cada peça fotográfica. A produção do mesmo teve por objetivo disponibilizar o catálogo seletivo na sala do Memorial, de forma a fornecer aos usuários, a trama em que as imagens foram produzidas e selecionadas para a composição da coleção fotográfica do $6^{\circ}$ Batalhão de Polícia Militar de Rio Grande.

Por último, mas não menos importante, a disponibilização das fotografias e suas descrições em um blog possibilitou a disponibilização externa a pesquisadores e usuários em potencial, dando à sociedade o conhecimento do acervo e sua história. Para se ter uma noção do alcance que a ferramenta possibilita, no período de janeiro a junho, obteve-se 306visitações online ao espaço. 
Por fim, acredita-se que as atividades de intervenção arquivística no acervo tenha sido de extrema importância, tanto para o conhecimento por parte da instituição de que existem meios e possibilidades de facilitar, difundir e enriquecer ainda mais o acervo ao qual custodiam, bem como do retorno que essas atividades possibilitam. Portanto, as atividades demonstraram uma nova perspectiva em relação às coleções fotográficas e utilização de intervenções arquivísticas nas mesmas, fornecendo igual valor de aplicabilidade que qualquer tipo de documento de arquivo.

\section{Referências}

ARQUIVO NACIONAL. Dicionário brasileiro de terminologia arquivística. Rio de Janeiro: Arquivo Nacional, 2005.

BELLOTTO, Heloisa Liberalli. Arquivos permanentes: tratamento documental. 4. ed. Rio de Janeiro: FGV, 2006.

BLAYA PEREZ, Carlos. Difusão dos arquivos fotográficos. In: Caderno de arquivologia, Universidade Federal de Santa Maria, Centro de Ciências Sociais e Humanas, Departamento de Documentação, Curso de Arquivologia. n.2. Santa Maria: UFSM, 2005. p.07-22.

CONSELHO NACIONAL DE ARQUIVOS (CONARQ). Recomendações para digitalização de documentos arquivísticos permanentes. [Rio de Janeiro]: Conarq, 2010.

FREUND, Gisele. Fotografia e sociedade. 2. ed. Lisboa: Vega, 1995.

GIL, Antonio Carlos. Como elaborar projetos de pesquisa. São Paulo: Atlas, 1991.

KOSSOY, Boris. História. 2. ed. São Paulo: Ateliê, 2001.

KOSSOY, Boris. Realidades e ficções na trama fotográfica. São Paulo: Ateliê Editorial, 1999.

LOPEZ, André Porto Ancona. Como descrever documentos de arquivo: elaboração de instrumentos de pesquisa. São Paulo: arquivo do estado, imprensa oficial, 2002. 64 p.

MOSCIARO, Clara. Diagnóstico de conservação em coleções fotográficas. Rio de Janeiro: Funarte, 2009.

PONTES, Renata Lopes; CASTRO FILHO, José Aires de. O uso do blog como ferramenta de ensino-aprendizagem por professores do projeto um 
computador por aluno (UCA). In: SIMPÓSIO BRASILEIRO DE INFORMÁTICA NA EDUCAÇÃO. 22., 2011, Aracaju. Anais [...]. Porto Alegre, Anais do WIE, 2011, p. 1478-1487.

PORTELLA, Viviane. Difusão virtual do patrimônio documental do arquivo público do Estado do Rio Grande do Sul. 2012. Dissertação (Mestrado em Patrimônio Cultural) - Universidade Federal de Santa Maria, Santa Maria, 2012.

PRIMO, Alex F. Teixeira; RECUERO, Raquel da Cunha. Hipertexto cooperativo: uma análise da escrita coletiva a partir dos blogs e da Wikipédia. Revista da FAMECOS, Porto Alegre, v. 10 n. 22, 2003, p. 5465.

RIBEIRO, Aldo Ladeira. Brigada Militar do Estado do Rio Grande do Sul: um monumento de tradição. Porto Alegre: Comissão Literária do Sesquicentenário da BM, 1987.

ROBERTS, Rebecca. Understanding museum archives. [200-?]. Disponível em: www.gslis.utexas.edu/ vmuseum/roberts.pdf. Acesso em: 12 jul. 2016.

SILVA, Edna Lúcia; MENEZES, Ester. Metodologia da pesquisa e elaboração de dissertação. 4. ed. Florianópolis: UFSC. 2005.

SILVA, Maria Celina Soares de Mello e. Arquivos históricos de museus: o arquivo de história da ciência do MAST. In: MUSEU DE ASTRONOMIA E CIÊNCIAS AFINS. Documentação em museus. Rio de Janeiro: MAST, 2008.

SILVA, Maria Celina Soares de Mello e. Arquivos de museus:

características e funções. Museologia \& Interdisciplinaridade, v. 2, n. 4, 8 out. 2013. 